\title{
Informação e memória de dança no Brasil, making off de um cd rom
}

Cássia Navas

Dentre as propostas instauradas experimentalmente na "REDE Stagium, centro de referências e de apoio à dança", aberta em 1996 pelos diretores do Ballet Stagium, Marika Gidali e Décio Otero, a planificação das bases de dados veio fortalecer a proposta mais ampla destes artistas-pioneiros: "buscar novas formas de apoio para gente de dança" e dentro desta filosofia também se desenvolveram programas de bolsas de estudo para criadores brasileiros.

A partir de uma experiência de doze anos com "informação em artes cênicas", no IDART (atualmente Divisão de Pesquisas/Centro Cultural São Paulo/Secretaria Municipal de Cultura), sabia que informações sobre dança eram de fundamental importância para o setor, fosse para a pesquisa, fosse para estratégias de intervençāo cultural, artística e política, fosse para o fortalecimento da prática individual e coletiva dos "povos da dança" de todo o lugar. Sabia também que, mediante o uso de novas tecnologias, o acesso às informaçōes poderia ser crescentemente democrático e generalizado.

A formatação de bases na REDE surgiu para se tentar formatos de disseminação em que as informaçōes fossem referentes a universos abrangentes e difundidos entre muitos. As propostas eram um tanto amplas (como o são todas as metas ideologicamente marcadas pelo traço da construção da cidadania cultural) e embasavam-se num argumento fundante: num mundo cada vez mais globalizado, onde as informações sobre tudo e todos se consumiam em bits e no piscar de uma emissão de TV, o que jogar na rede a respeito de um topus chamado "dança do Brasil"?

Se a questão era a de colocar este topus nas janelas das infoways, restava saber com que semblante nelas apareceríamos, a construção das bases constituindo-se uma iniciativa importante para a definição de perfis e para uma reflexão sobre os mesmos.

Ao se pensar em um banco de dados especializado, aspectos de sua definição strictu sensu foram levantados, questionando-se a pertinência e as características de uma empreitada desse tipo, sobremaneira aquelas que dizem respeito à quantidade e qualidade de informações, e mais ainda à forma em que estas últimas se organizam, permitindo-se o cruzamento e a recuperação de dados.

Quando a primeira base de dados foi construída (festivais, mostras e encontros

Cássia Navas ẻ pós-doutora em dança pela ECA/USP e especialista em gestão, ação e políticas culturais (Université de Dijon/Ministério da Cultura da França/UNESCO). Coordenou a REDE Stagium durante cinco anos e dirige a Oficina Cultural Oswald de Andrade. 
de danças do Brasil - julho/1996), a partir de uma listagem parcial (1994, Coordenaçăo de Dança/FUNARTE/Minc) o desenho prévio de um banco de dados se concretizou em três referencialidades básicas:

1. quantidade, pois tínhamos um número suficiente de informaçōes, quando estas eram analisadas à luz do montante de ocorrências às quais se referiam, num determinado meio ambiente cultural;

2. qualidade, visto à possibilidade de contar-se com informações de qualidade, sobretudo em termos de atualizaçäo de dados;

3. formato, posto que as informaçōes eram articuladas em critérios teóricos e informacionais compativeis, sendo que o principal ganho seria uma disseminação que prescindisse do auxílio de um profissional especializado no assunto, servindo da mesma maneira a especialistas, profissionais e público em geral.

As informações contidas na base de 1996, e nas posteriormente publicisadas no cd rom informação e Memória de Dança no Brasil, Levantamento de coreógrafos, companhias/grupos e escolas/academias do Estado de São Paulo (2001, REDE Stagium/ Associação Ballet Stagium, SESC São Paulo e a Secretaria do Estado da Cultura, São Paulo), eram de natureza especial em pelo menos dois sentidos: revestiam-se de ineditismo e referiam-se a um universo especializado.

Apesar das dificuldades inerentes a um projeto desta natureza realizado em uma "organização não-governamental" de arte/cultura, através do apoio fundamental do SESC São Paulo e da Secretaria do Estado da Cultura, pode-se levar adiante a planificaçāo, realização e publicisaçăo de informaçōes que apontavam para os meios da dança (como cultura, arte com história e forma de conhecimento do mundo) e as especialidades das formas de linguagens por eles estruturadas, mediante um complexo reticulado de métiers.

\section{Informação em dança: duplo trabalho com o transitório}

O trabalho com informação cultural muitas vezes se torna uma atividade com o "invisível": volátil e delicado não pode prescindir das várias matizes da obstinação e transforma os pesquisadores que a ele se dedicam em pessoas de perfil específico.

Ao invés de um certo tipo de "frustração" crônica, que costuma acompanhar aqueles investigadores da academia que perscrutam hipóteses pontuais de trabalho, entre os "pesquisadores-da-informação", a insatisfaçāo se dá mais a nível do tempo que passa, e rápido. A partir do instante em que é colhida, cada informação corre 0 risco de se desatualizar. A insatisfaçăo é, nesse caso, com o signo do transitório e nāo com um certo tipo do "duvidar", presente no estado de uma pesquisa mais acadêmica.

Os "povos da dança" estăo bastante habituados a lidar com a transitoriedade das ações, já que sua arte é, marcadamente, uma arte do tempo, construindo-se no espaço e temporariamente aos olhos de quem a observa, seja a imagem especular refletida nas paredes dos estúdios, seja o olhar do público, professores, colegas, crít-

130 -.. Novembro $2004-N^{\circ} 6$ cos. Tal característica traz às formas da linguagem da dança maneiras peculiares de deixar traços atrás de si, índices que, em sua história, foram sendo transformados com os adventos da litogravura, da foto, cinema, vídeo e imagem sintética.

O trabalho com informação em dança é um trabalho dentro das "escrituras sobre a dança", uma arte que se atualiza no tempo em que ela se perfaz, e que por isso parece ser feita - exclusivamente, durante o tempo em que está sendo realizada.

O perene recomeçar é alimentador de uma circunstância com a qual nos deparamos com freqüência, quando se iniciam cursos sobre a história dessa arte: toda vez que as aulas recomeçam, tudo parece começar do zero. Este estado de coisas também se deve a uma certa ausência de índices mais organizados (livros, vídeos, apostilas) apresentando-se uma circunstância fundamental, que remete a estratégias pedagógicas e de criação relacionadas às questōes da oralidade.

Durante vários séculos a transmissảo dos conhecimentos de dança deu-se através de estratégias de transmissão oral, de onde a importância dos mestre-coreógrafos, que são uma fundamental parte da memória da dança, os seus rapsodos. Se a "oralidade" merece toda uma reflexão mais aprofundada dentro da história da dança e suas veredas de formaçăo, criação e difusão, cada vez mais os índices de tais caminhos, sobretudo aqueles que hoje estão sendo traçados, são absolutamente necessários.

\section{Bases na REDE, $1^{1}$ fase}

Em 1997, começamos a planejar as bases coreógrafos, escolas e companhias. Haja vista a enorme empreitada que teríamos pela frente e a necessidade de apoiar institucionalmente nossas açōes, para além das açōes de uma associação historicamente ligada a uma escola e companhia de dança, tornou-se imprescindível uma parceria entre a Associaçāo Ballet Stagium e uma instituição paulista que pudesse validar de várias maneiras, financeira e culturalmente (BOURDIEU, 1992: 43), um trabalho pioneiro e por isso acentuadamente experimental.

A parceira com o SESC incluía um trabalho com os núcleos dessa entidade, espalhados pela capital e interior, através das açōes de seus técnicos, que em princípio, de maneira imediata e mais descentralizada, tinham condições de nos trazer informaçōes sobre o terreno: tinham o mapa local, fruto das ações nos territórios regionais onde estāo localizados cada unidade.

A proposta se delineava: necessitávamos elaborar três "questionários específicos" relativos a "três unidades básicas de pesquisa" que teriam que ser definidas: coreógrafos, escolas/academias e companhias/grupos. Para fazê-lo resolveu-se ouvir a comunidade da dança, representada por alguns de seus profissionais, através de seis encontros específicos, cada um deles dedicado a um tema geral.

Desses encontros internos, posto que não facultados a qualquer espécie de público, participaram Marika Gidali (Ballet Stagium), Ruth Rachou (Espaço de Dança Ruth Rachou), Ismael Guiser, Esmeralda Penha Gazal (Escola Municipal de Bailados), Gil- 
samara Moura (Grupo Gestus/Araraquara), Laís Lima, Hulda Bittencourt (Cisne Negro Cia. de Dança), Mário Nascimento (representando o Balé de Rio Preto), Rosely Rodrigues (Grupo Raça), Adriana Grechi, Tica Lemos, Lucilene Favoreto (Cia. Nova Dança), Renée Gumiel, J.C. Violla, Renata Melo, Célia Gouvêa, Eliana Carneiro, Luís Arrieta, Marcos Bragato, Carlos Martins (Cooperativa Paulista de Bailarinos-Coreógrafos) e Antônio Carlos de Moraes Sartini (Departamento de Formaçāo Cultural/SEC).

\section{Unidades de pesquisa: escolas, companhias, coreógrafos}

Para além de um "afinamento" dos universos filosófico, teórico e técnico do "projeto bases", essas reuniōes constituíram-se em exercícios saturados de história e cidadania em dança, e, através dos debates, pusemos à prova determinadas hipóteses iniciais de elaboração dos questionários. Deles também resultou a constatação de serem ainda as escolas/academias as unidades fundamentais de produção de dança, seja ela qual for.

As companhias seriam um projeto/esforço coletivo - reunião de bailarinos, coreógrafos, técnicos, apoiadores em geral -, dentro do qual se enfeixam saberes e fazeres, levados adiante pela vontade de um líder, ou líderes, cujo norte é o desejo de viver de dança. Geralmente essa liderança é exercida por um coreógrafo - aquele que escreve a dança, compõe o espetáculo e que geralmente ensina, difunde e cria "movimentos". Através dessa figura, o "mestre-coreógrafo", se imbricam as atividades e trajetórias das escolas/academias e aquelas das companhias/grupos de dança

O coreógrafo é um artista onde o desejo do trabalho com dança se manifesta de maneiras várias, mas geralmente aparece depois de uma carreira onde se "trabalha com o corpo". Os criadores geralmente tiveram alguma experiência corporal anterior em dança, teatro, ginástica ou esporte.

Em sua maioria, as trajetórias em dança originalmente se estruturam depois de uma manifesta sensação de "querer dançar". Esse "desejo" parece chegar quase como uma revelação - uma espécie de "vontade revelada" - que vai se materializando com dificuldade, devido à falta de estruturação de uma carreira socialmente pouco reconhecida ou nem mesmo, na grande maioria dos casos, cultural e institucionalmente estabelecida, através de uma escola ou faculdade.

A partir dessa "revelação", difusamente patinada por uma espécie de "sedução de querer seduzir pelo movimento", vem o árduo trabalho para a construção de uma trajetória que é dura, e durante a qual se encontram muitas dificuldades.

Para ser coreógrafo, geralmente têm-se a necessidade de outros bailarinos, quase sempre alunos, e dessa forma, torna-se necessária uma escola, muitas vezes pólo de subsistência, garantido por um "amor ao negócio", que se manifesta sem tréguas.

Para se ter uma escola e/ou companhia trabalha-se muito e arduamente, os passos sendo anunciados, de maneira retrospectiva com uma imensa necessidade de afirmaçāo a cada momento: afirmaçōes relativas à responsabilidade e seriedade de açöes, necessidade da luta constante, marcada por percalços de toda natureza.

Muitas vezes determinados aspectos dessa espécie de "ascese" são somente insinuados, vislumbrando-se "estratégias" um tanto encobertas, o que muitas vezes traz a impressão de uma certa avareza na enunciação de informaçōes relativas a oportunidades.

Em dança, a "oportunidade", enquanto uma conjuntura favorável ou oportuna de tempo e lugar para que se dê ou se realize algo, geralmente se deve ao trabalho de construção de cada um de seus atores, já que "oportunidades" institucionais são raras e por isso mesmo altamente disputadas.

\section{2a fase: ação-piloto em Campinas, São José do Rio Preto e capital}

Depois dos encontros, foram elaborados modelos de três questionários relativos às bases de dados que iríamos construir: os questionários-piloto. A extensão inicial desses modelos tentava abarcar vários aspectos das trajetórias, histórias e práticas contemporâneas de cada estrutura ou artista investigado, além de tentar através das questōes articuladas entre si, levantar a situaçāo de cada uma das "unidades de pesquisa", com vistas a sua inclusão ou não nas bases de dados que se iria estruturar.

Em princípio, nem todos aqueles que responderam aos questionários foram incluídos nas bases, posto que fora prevista uma seleção, que seria arbitrada conjuntamente pelos técnicos da REDE e do SESC. A seleção não foi embasada em juízos de valor sobre o trabalho realizado em cias/grupos, escolas/academias e por artistas-coreógrafos, e muito menos excludente de qualquer circuito de produção e difusão da dança de nosso estado, fugindo-se de classificaçōes de universos comum e rapidamente taxados por vocábulos como contemporâneo, moderno ou clássico.

As premissas dessa seleção seriam resultados de critérios múltiplos e inter-relacionados. Parte desses critérios seguiu explicitada nas capas de cada questionário, como a clareza no fornecimento de informaçōes e responsabilidade sobre as mesmas. Outros, que se referiam à inclusăo de profissionais e/ou de estruturas da cultura diziam respeito a questōes gerais como permanência, visibilidade e produção (de informaçōes e de produtos artísticos) de escolas, companhias e coreógrafos.

Todos juntos resultaram no universo técnico com o qual se trabalhou, abaixo esquematicamente descrito:

permanência: dentro desse núcleo, pretendia-se avaliar a regularidade com que o profissional, escola e/ou companhia aparecesse no "mercado de trabalho" e as direçōes de sua trajetória face ao universo da dança;

visibilidade: nesse núcleo, o objetivo era o de verificar a "medida" de quanto o profissional e/ou estrutura cultural se dá a conhecer, seja através dos meios de comunicação de massa (local, regional ou estadual), mídia especializada, festivais, premiaçōes e participação em atividades culturais variadas;

produção : referia-se à identificação de sinais relativos aos produtos gerados 
pelo trabalho e trajetória de cada escola, companhia e coreógrafo, através de suas características, constância e regularidade e da medida em que cada produção, ou o seu conjunto, possa ser considerada fator de inserção em determinado meio ambiente artístico-cultural.

Até aquele momento, não sabíamos que tipo de problemas de distribuição, veiculação e retorno iríamos enfrentar, mas o trabalho dentro desse universo técnico nos garantiu a qualidade das informaçōes, assim como a envergadura do tratamento qualitativo, que pressupõe uma capacidade de escolha e descarte informacional de natureza profunda.

No teste piloto de fevereiro de 1998, 30 questionários foram distribuídos pelas cidades de Campinas, São José do Rio Preto e São Paulo, sendo que dezesseis deles foram respondidos, numa média quantitativa de resultados que reputamos aceitável.

$\mathrm{O}$ que mais nos incentivou na continuação do projeto foi a qualidade das respostas e a extensão dos textos em algumas das questões abertas, sobretudo aquelas destinadas às "observaçōes gerais", uma item que se seguia (nos três questionários) depois de todos os outros, ou seja, deveria ser respondido (ou não) após um árduo trabalho de reflexão e levantamento de histórias institucionais e pessoais, obviamente mobilizador de emoçōes e reflexões, muitas vezes duras de serem ultrapassadas.

A partir da ação-piloto, foram re-elaborados os questionários definitivos, que depois do lançamento oficial do projeto (realizado em novembro de 1998 no SESC Pompéia, em novembro/dezembro desse ano nos SESCs Baurú e São Carlos e em fevereiro de 1999 no SESI/SESC Araraquara) foram distribuídos por todas as unidades do SESC São Paulo.

A decisão de se manter o questionário em sua quase integridade inicial, deu-se pela oportunidade única e original do levantamento que deveríamos fazer, mas sobretudo pelo fato de que, os questionários respondidos neste teste inicial, o foram em sua quase total extensão, sendo que a opção continuou sendo a de uma mostragem de caráter mais qualitativo, melhor dizendo "qualificado", onde as informaçōes seriam tratadas de duas formas básicas: "campos controlados" e "campos de texto livre".

\section{3a fase: questionários definitivos}

Para o lançamento do projeto, em suas feiçōes definitivas foram:

1. re-organizados os cadastros de dança da REDE;

2. definidos o número e a tipologia de locais onde os questionários seriam distribuídos, já que cada unidade do SESC atua em algumas das cidades que são circunvizinhas ao município que lhe abriga;

3. definidos os técnicos que iriam se ocupar do trabalho na capital e no interior;

4. elaborado e aplicado um treinamento, no qual estavam incluídos: introdução histórica, fundamentos, objetivos e procedimentos básicos;

5. elaboração de um plano de recebimento de questionários pela REDE Stagium;
6. elaboração de um plano de tratamento e digitação dos dados, coordenado pela REDE em comum acordo com o SESC Sāo Paulo.

A todo o momento eram questionados os motivos que levariam os atores da dança do estado a estarem colaborando nessa proposta, apesar de que a construção de um mapa de um meio artístico específico nos parecesse de fundamental importância, pois antes da REDE, exclusivamente em dança, ninguém havia se lançado a essa tarefa, dentro de padrōes profissionais semelhantes.

Depois de lançado o projeto, diferentes iniciativas de cadastro de informaçōes em dança surgiram no panorama brasileiro, como as da FUNCART (Londrina) e Instituto Cultural Itaú (Säo Paulo), sendo que em 2.000, a Coordenação de Dança (FUNARTE/Ministério da Cultura) publicou um levantamento parcial das companhias/grupos do país, denominado Brasil Dança 2.000: construindo um perfil.

Dado o ineditismo inicial das bases da REDE, tínhamos convicçăo de estarmos nos movendo dentro de estratégias e terrenos experimentais, para os quais talvez devêssemos ter planejado outras táticas de divulgaçăo, além da postagem de folders específicos sobre o trabalho (anteriormente às mesas de lançamento), nos quais foram explicitados as propostas gerais.

Em termos de disseminação de informação da proposta em si, acreditava-se que o próprio questionário jogaria um papel fundamental, constituindo-se num instrumento de contaminação de um determinado ambiente cultural. Cada questionário era acompanhado de um "kit" informativo, composto de uma página de rosto e uma carta explicativa, onde, além das questões técnicas, arrolava-se os produtos principais do trabaIho: bases de dados veiculadas em cd rom. Os subprodutos seriam um cadastro especializado e uma mala direta mais atualizada.

Distribuídos os questionários no final do ano de 1998, fixamos um prazo inicial de devolução para fevereiro de 1999. Nessa terceira etapa do trabalho, não nos foi possível saber a quantidade exata de questionários distribuídos, por intermédio das 10 unidades do SESC da capital e das, àquela época, 11 unidades do SESC no interior. O monitoramento desses números tornou-se impossivel em virtude da verdadeira descentralização de atribuiçōes de cada unidade e pelo fato de os questionários poderem ser reproduzidos pelas pessoas que os recebessem, numa maneira de se intensificar cada vez mais a sua difusāo, sendo que todo o material também estava facilmente disponível no site do SESC São Paulo.

Alguns questionários foram postados pelo correio, outros tantos (principalmente nas cidades de São José do Rio Preto, São Carlos e Araraquara) foram quase que totalmente distribuídos de porta em porta, numa espécie de proto-rescenceamento de uma comunidade específica.

No final de fevereiro, ao fazer uma avaliação prévia dos resultados, resolvemos nos lançar numa última empreitada de divulgação da proposta. A TV Cultura/programa Metrópolis, O Estado de São Paulo, o Aplauso/Jornal do SATED-Sindicato dos Artistas e Técnicos de Espetáculo e o Diário de São José do Rio Preto novamente divulgaram a 
iniciativa, esclarecendo sua estrutura e prazos.

Essa última cartada, pensada como um instrumento para incentivar o preenchimento de mais questionários, sobretudo pelos responsáveis por instituiçōes e artistas baseados na capital do estado, provocou reações interessantes.

Muitos não haviam recebido os questionários, por não constarem do cadastro básico inicial e ligaram entre curiosos, desconfiados e mesmo ofendidos pelo que consideravam ser uma atitude de exclusāo. A todas eles foram enviados novos "kits de questionários". De outro lado, muitas das pessoas que haviam recebido o material entraram em contato com a REDE e com alguns técnicos do SESC para colocarem as razōes de sua demora em participar do projeto e entre certos componentes desse último grupo persistia um certo ar de culpabilidade, pois se achavam importante a iniciativa, nảo tinham conseguido ainda dela fazer parte.

As reportagens também ocasionaram uma certa "corrida" de profissionais de outros estados (e de brasileiros residindo no exterior) querendo participar do projeto. Alguns deles (cerca de seis) já haviam respondido aos questionários, pois, por erro de postagem, alguns questionários foram enviados a cidades fora do estado.

Os questionários de coreógrafos de outros estados, além daqueles referentes a criadores brasileiros que residem na Bélgica e Estados Unidos, encontram-se no acervo da REDE/Ballet Stagium, tal como acontece com todo o material residual do trabalho com as bases: questionários já tratados, programas, folhetos, cartazes, fotos, material de imprensa e videográfico.

\section{4a fase: análise de dados e retomada}

A partir das reportagens esperamos mais trinta dias e demos por encerrada a coleta de dados, constatando-se que a maior parte dos questionários respondidos tinha origem no interior de São Paulo, tipologia que prevaleceu nas listagens divulgadas no cd rom.

Estranhamente os artistas e produtores da cidade de São Paulo pareciam ter tido um interesse incrivelmente menor em estar participando dessa iniciativa, o que nos levou a pensar que ao sentirem mais presentes dentro de um circuito de difusão/validação mais visível ou atuante tivessem descartado esta outra possibilidade de visibilidade profissional, característica que os diferenciaria de seus pares de cidades do interior.

Também por estas ausências foram enviados novos questionários por SEDEX, iniciando-se um acompanhamento especial do preenchimento de cada um deles, incluindo-se as mais variadas estratégias de "sedução": telefonemas, e-mails, cartas, visitas, fax, nova remessa de questionários, telefonemas e etc.

Esperados os retornos até fevereiro de 2.000 , definitivamente, encerrou-se a coleta de informações e por este motivo, na elaboração das três bases temos três núcleos de informações, no que toca à sua atualização:

1. informaçōes que vão até meados de 1998 (testes pilotos),
2. informaçōes que vão até o final de 1998 ( $1^{\text {a }}$ etapa de distribuição/coleta/ análise) e

3. informaçōes que vão até o final de 1999 (2ª etapa de distribuição/coleta/ análise).

\section{5a fase : resultados abrangentes na diversidade}

Depois de tratados os questionários e analisados esses três núcleos cronológicos de informação, a questão seria a inclusāo/exclusão dos registros relativos à cada base de dados, iniciando-se o trabalho com os conceitos do universo técnico, que nos faria também retornar às questōes originais, levantadas nos encontros com os profissionais que deram início a todo o processo.

Devido a estas análises, alguns dos registros relativos a questionários tiveram que ser excluídos. Via de regra eles dizem respeito a coreógrafos, escolas ou companhias de dança que não se enquadravam no critério visibilidade e produção de bens culturais, em seu sentido amplo.

Por outro lado, constatou-se que alguns profissionais integrantes das bases publicisadas não teriam se dedicado a preencher todos os itens onde a "visibilidade e/ou constância" de suas atividades culturais pudesse ser aferida com mais acuidade. Nesses casos, os técnicos que trataram as informações por eles fornecidas não poderiam inferir a existência dessas atividades a partir de outras questões ou mesmo dos currículos anexados.

\section{Cadastro e fonte de pesquisa}

Quanto à totalidade das informações, caberá aos consulentes do cd rom perceber certas nuances da história de coreógrafos, companhias/grupos, escolas/academias, reveladas em várias possibilidades de apreensão. Por este viés, o levantamento realizado pode ser apreendido em diversos níveis: da consulta de um cadastro até a investigaçăo de um campo determinado, nesse caso, demandando-se do leitor a paciência de garimpeiro ou de ourives necessárias a um bom pesquisador.

Se num desses pólos- a consulta de um cadastro, muitas vezes faltarão informaçōes, que se espera ver coletadas em outros momentos e espaços, no que toca ao segundo nível, o material é de uma riqueza caleidoscópica. Tomemos um único exemplo.

$\mathrm{Na}$ análise de certos registros, depreende-se que certos coreógrafos, na listagem das obras de sua autoria, mais de uma vez arrolaram espetáculos de teatro e de dança onde o autor principal seria um outro metteur en scène ou criador-coreógrafo que não eles próprios.

Nesses casos, estabelece-se um campo difuso entre o "coreografar ou iluminar uma cena" e o "o dançar ou se ter concebido um espetáculo", os coreógrafos, ilumina- 
dores e intérpretes sentindo-se conjuntamente autores de uma mesma obra de teatro e dança.

O mesmo pode acontecer em casos de coreógrafos que criaram excertos coreográficos dentro de obras mais extensas, aqui também se estabelecendo uma discussão que remete à rica tessitura intersemiótica e interautoral pela qual se compõe qualquer espetáculo.

\section{Abertura para reflexão e ações centrais e regionalizadas}

Com respeito à exclusăo/inclusảo de certas "unidades de pesquisa", os critérios de "permanência e visibilidade de produção" foram problematizados caso-a-caso, em função do ambiente em que cada unidade de pesquisa estivesse inserida - cidade regiảo, zona ou bairro, tentando-se escutar a validação de cada local, pelas açōes dos que aí vivem.

Trabalhou-se com "redundâncias", num processo que se iniciou aberto e foi se construindo, em muitas de suas sendas, no decorrer dos acontecimentos. Muitas das dificuldades poderiam ter sido sanadas com um retorno dos questionários às "unidades básicas de pesquisa", atitude que nesse levantamento năo pudemos tomar. Ou seja, não se trabalhou com um vai-e-vem personalizado de informaçōes entre técnicos e membros da comunidade de dança.

Também temos que considerar uma certa "resistência" frente ao projeto em si, visível e sentida em muitos dos momentos do trabalho, manifestada nos questionários não respondidos, nas desculpas e explicaçōes de toda a natureza. Paralelamente a isso, tínhamos a consciência de que, mesmo com o enorme esforço despendido, não tínhamos conseguido alcançar a todos em toda a parte.

Nem todas as regiões foram bem "planfletadas" e se, em princípio, fechamos o trabalho sobre as "cidades médias" do estado (mais de 80.000 habitantes) ou sobre municípios menores, desde que com eles o SESC São Paulo mantivesse um intercâmbio ou um trabalho específico ("Challange Day" ou "Caminhão Lorca"), nem mesmo todos esses locais foram alcançados pelo projeto.

A falta de um maior engajamento no processo pode ser avaliada sob diversos pontos de vista, além dos já apontados, como a dificuldade em "revelar-se as oportunidades", índice que pode ser incluído dentro de um dos traços formadores da "resistência e persistência" de uma grande gama de construtores da dança, para os quais o segredo continua a ser de ouro.

Pode-se pensar também na clássica dificuldade dos profissionais da dança relativa a um "falar sobre si mesmos" e sobretudo de estabelecer sobre essa fala uma escritura organizada, muitas vezes empreitada já realizada em outros formatos - curriculos ou press releases, suportes anexados aos dossiês e aos quais alguns profissionais fizeram referência.

No cd rom, a citação de tais documentos aparece como uma nota, posto os téc- nicos não terem tido a possibilidade de escolher, nos currículos, as informações que mais Ihes parecessem importantes. Essa deveria ter sido a ação de cada indivíduo e/ou responsável pela estrutura cultural investigada. Nessas "ausências manifestas" (expressas nos apontamentos de "vide currículo") nada pudemos fazer.

Novamente se faz necessário frisar a marcante ausência dos profissionais da dança da capital, que enquanto uma coletividade não se vincularam ao projeto. Como explicar tal lacuna? A hipótese mais forte ainda é a de que os "artistas da capital" talvez compartilhassem entre si um difuso sentimento de já contarem com uma visibilidade suficiente, garantida pelo fato de terem acesso a mais (ou mais poderosos) circuitos de validação de seus trabalhos: jornais, festivais/mostras e instituições de referência em pesquisa, ensino, criação e formação.

Uma maior resposta do interior pode ser analisada sob o mesmo ponto de vista: carentes de circuitos de visibilidade, os profissionais têm consciência de que qualquer chance de divulgação de seu trabalho e validação de sua história deva ser aproveitada.

Por fim, o levantamento publicado no cd rom Informação e Memória de Dança no Brasil, Levantamento de coreógrafos, companhias/grupos e escolas/academias do Estado de São Paulo veio de encontro a grande parte de suas metas iniciais, a elas agregando outras constataçōes. São elas:

1. aumento de visibilidade (dentro e fora do SESC Săo Paulo e da Secretaria do Estado da Cultura) aos membros da comunidade da dança que dele participaram;

2. constituição de uma oportunidade histórica de um mapeamento de profundidade;

3. apontamento da necessidade de um maior número de informações sobre a área, imprescindível para o aumento da cidadania no setor;

4. desvelamento de uma parcela de atores culturais que a sociedade civil não conhece e que tampouco se conhecem muito bem;

5. fortalecimento de uma rede de recorrências entre os pólos de uma comunidade específica, através do apontamento de suas características atuais e aquelas de sua formação enquanto universo histórico e portanto, de um tempo e lugar;

6. quebra de tabus, sobretudo aqueles relativos a uma "arte sem história" - na verdade arte "sem história escrita", que tem que ser recomeçada do início, a todo o tempo, sem cessar, relegando-se a sua memória à palavra de alguns que fragmentadamente detenham os seus saberes, muitas vezes ao sabor dos poderes instituídos, sejam eles quais forem.

O resultado desta parceria entre a Associação Ballet Stagium e SESC São Paulo, através do projeto REDE, concretizou-se em ferramenta de intervenção em dança. Ao abrigar em listas de fato abrangentes, profissionais e estruturas que se dedicam a construir a cultura da dança de um estado, trabalhou-se com a convicção de que o apontamento das variantes das quais se compõe a múltipla diversidade da sociedade brasileira é um dos caminhos para mais e melhores açōes democráticas.

Ações da polis, e portando, políticas em seu sentido amplo e original. 
BOURDIER. P. Les Règles de l'Art. Genèse et Structure du Champ Littéraire. Paris, Seuil, 1992.

NAVAS, C. Os Desenhos dos Desenhos da Dança. texto do catálogo da exposição Desenhos de Dança. São Paulo, AS Estúdio, 1996

NAVAS, C. Dança e Mundializaçáo: Políticas de Cultura no Eixo Brasil-França. São Paulo: Hucitec, 1999.

TEIXEIRA, M. Brasil Dança 2.000: Construindo um Perfil. Rio de Janeiro: FUNARTE, 2000. 